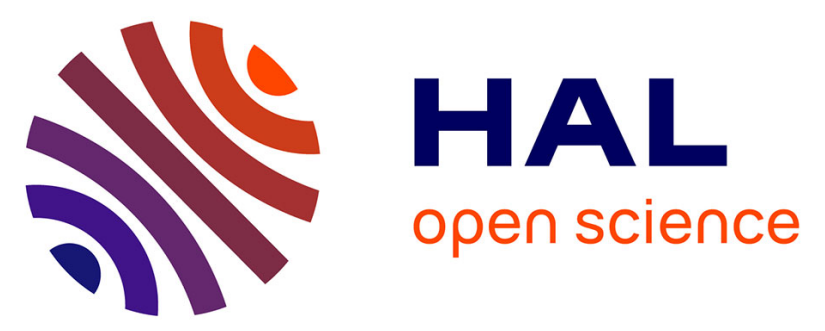

\title{
Spill-back events followed by self-sustainment explain the fast colonization of a newly built marina by a notorious invasive seaweed
}

Mathilde Salamon, Laurent Levêque, Marion Ballenghien, Frédérique Viard

\section{- To cite this version:}

Mathilde Salamon, Laurent Levêque, Marion Ballenghien, Frédérique Viard. Spill-back events followed by self-sustainment explain the fast colonization of a newly built marina by a notorious invasive seaweed. Biological Invasions, 2020, 22 (4), pp.1411-1429. 10.1007/s10530-019-02193-5 . hal-02860993

\section{HAL Id: hal-02860993 https://hal.science/hal-02860993}

Submitted on 9 Jun 2020

HAL is a multi-disciplinary open access archive for the deposit and dissemination of scientific research documents, whether they are published or not. The documents may come from teaching and research institutions in France or abroad, or from public or private research centers.
L'archive ouverte pluridisciplinaire HAL, est destinée au dépôt et à la diffusion de documents scientifiques de niveau recherche, publiés ou non, émanant des établissements d'enseignement et de recherche français ou étrangers, des laboratoires publics ou privés. 


\section{Authors (names, affiliation, e-mail addresses)}

Mathilde Salamon ${ }^{(1,2)}$

Laurent Lévêque ${ }^{(3)}$

Marion Ballenghien ${ }^{(1)}$

Frédérique Viard ${ }^{(1)}$

(1) Sorbonne Université, CNRS, Lab. Adaptation and Diversity in Marine Environments (UMR 7144 CNRS SU), Station Biologique de Roscoff, Place G.Teissier, 29680 Roscoff

(2) present address : Départment des sciences biologiques, Université du Québec à Montréal (UQAM), P.O. Box 8888, Succursale Centre-Ville, Montréal, Québec, Canada, H3C 3P8

(3) Sorbonne Université, CNRS, Fédération de Recherche (FR 2424 CNRS SU), Station Biologique de Roscoff, Place G.Teissier, 29680 Roscoff

Author for correspondence: Frédérique Viard, ORCID no. 0000-0001-5603-9527, viard@sb$\underline{\text { roscoff.fr }}$

\section{Running head}

Demo-genetic surveys of the colonization dynamics of Undaria pinnatifida

\section{Acknowledgments}

The authors gratefully acknowledge the divers the Marine Operations Department (Service Mer \& Plongée) of the Roscoff Marine Biological Station (Mathieu Camusat, Yann Fontana, Wilfried Thomas), Caroline Broudin, Ronan Garnier, Sarah Bouchemousse for their help during field surveys and sampling. The authors are also grateful to the marina Director (Frédéric Boccou) and to Patrick Podeur from the Biocéan company who allowed us to conduct these surveys and sampling in the marina and the farm, respectively. We are most grateful to the Biogenouest Genomer core facility for its technical support. This work benefited from the support of the French National Research Agency (ANR) with regards to the IDEALG project (ANR-10-BTBR-04). 


\section{Abstract}

Biological invasions are occurring at increasing rates since the onset of the $20^{\text {th }}$ century. While ports and marinas have been identified as a major point-of-entry for the spread of marine non-indigenous species (NIS), their relationships with wild habitats however needs further scrutiny. We had the rare opportunity to monitor the real-time colonization dynamics of a newly-built marina by the notorious invasive kelp Undaria pinnatifida in the Bay-of-Morlaix, Brittany (France). Field surveys ( $>20000$ individuals geo-localized) were combined with genetic analyses (10 microsatellite loci, $\mathrm{N}=890$ individuals) over three years (i.e., 6 generations in the study area). Regarding the colonization dynamics, a dramatic snow-ball effect was documented over time, with local density reaching up to 50 individuals per $m$ after two years. Assignment tests showed that the primary colonizers came from neighboring populations established in natural rocky reefs. A shift towards a self-sustaining population was however observed the following year, with $44 \%$ of self-assignment. These processes are best explained by i) life history traits, notably rapid growth and selfing, and ii) natural dispersal within the marina combined with human-mediated dispersal - through leisure boating- over longer distances. Spill-over effects have been previously documented, and here also reported, to explain the expansion of $U$. pinnatifida from marinas to the wild. We showed that the on-going ocean sprawl also offers a perfect arena for spill-back events (i.e., spread from natural habitats to artificial structures), highlighting the need for careful surveillance of newly built infrastructures.

Keywords: Undaria pinnatifida, artificial habitats, rocky reefs, dispersal, population genetics, spatial analyses 


\section{Introduction}

The ocean sprawl (i.e., the increase in artificial structures along the coasts; Duarte et al. (2013)) is a major process affecting marine coastal environments, notably by favoring the introduction and establishment of non-indigenous species (NIS) (Firth et al. 2016). In marinas, NIS represent a major component of the flora and fauna (Airoldi et al. 2015; Bishop et al. 2015; Glasby et al. 2007). These marine urban habitats are considered as invasion hubs promoting the spread of NIS towards natural habitats (i.e., spill-over effects, Airoldi et al. 2015; Bulleri, Chapman 2010). Recreational vessels, neglected for a long time, are indeed increasingly recognized as vectors transporting introduced species over a large range of distances (Clarke Murray et al. 2011, Mineur et al. 2008, Ulman et al. 2019). Once marine NIS are established, eradicating them proves to be difficult and cost-inefficient in most cases (Ojaveer et al. 2015; Simberloff et al. 2013). Management of invasive species has been found to be more likely to succeed and less economically damaging when efforts are focused on curtailing the vectors and pathways (Lodge et al. 2016; Pyšek, Richardson 2010). Understanding the interactions between wild and marina populations is critical, notably to define management strategies and prioritize targets in surveillance programs.

Field surveys, combined to DNA-based studies, can help uncover the connectivity patterns between populations occupying artificial and natural habitats (Rius et al. 2015). We carried out this approach, using the seaweed Undaria pinnatifida Harvey (Suringar, 1873) (Laminariales, Alariaceae) as a case study. This brown alga is an iconic invader: it became established worldwide in less than 30 years, through global shipping and aquaculture (Epstein, Smale 2017; South, Thomsen 2016). In Europe, it was first introduced accidentally in the Mediterranean Sea, presumably by aquaculture imports of the Pacific oyster from Asia, then deliberately transported on the NW coasts of France (Brittany) to be cultivated. In Brittany, colonization of surrounding natural and artificial habitats was rapidly observed nearby these farmed populations (Floc'h et al. 1996), indicating that the cultures were the primary source of new populations in the wild in Brittany. This hypothesis was later confirmed with genetic studies (Voisin et al. 2005). However, in its non-native range, U. pinnatifida shows preference for artificial structures (Epstein, Smale 2017; Epstein, Smale 2018a; Epstein, Smale 2018b; Guzinski et al. 2018; South, Thomsen 2016). A recent population genomics study, carried out in Brittany, showed that populations in natural rocky reefs are genetically similar to marinas rather than farms, suggesting on-going spill-over processes from marinas to the wild, rather than from farms to the wild (Guzinski et al. 2018). These DNA-based results are congruent with results obtained from field surveys, documenting spill-over events in areas where no farms exist so far (Epstein, Smale 2018b).

U. pinnatifida is a short-lived, selfing species (e.g., 2 generations per year in the English Channel), with an annual heteromorphic life cycle of alternating macroscopic diploid sporophytes and microscopic 
haploid gametophytes. Its opportunistic nature may provide advantages to colonize artificial structures such as marinas, seawalls, buoys etc. (Sliwa et al. 2006). Dispersal of Undaria by leisure boating or larger vessels has been documented (South et al. 2017). In addition, spores can survive in bilge water, and gametophytes germinating from spores are able to grow on hulls, anchoring systems, and ropes (Bollen et al. 2017). However, the relative contribution of natural and human-based dispersal needs further scrutiny. Natural dispersal by spores and gametes is indeed expected to occur at very short distances $(<10-100 \mathrm{~m}$, Forrest et al. 2000), even though spores can survive 1-2 days and be washed away by the tidal currents (Saito 1975b). Drifting mature sporophytes might also be responsible of dispersal over larger distances (1-10km, Sliwa et al. 2006). As pointed out by Guzinski et al. (2018), these natural means of dispersal are nevertheless unlikely to explain the chaotic genetic structure observed at a regional scale, suggesting that dispersal by recreational vessels play a predominant role in connecting distant $(>10 \mathrm{~km})$ sites. Yet, in a context of increasing ocean sprawl, it is unclear to which extent and at which rates novel substrates can be colonized, and through which dispersal means (South et al. 2017).

Previous studies (e.g., Epstein, Smale 2018b; Grulois et al. 2011; Guzinski et al. 2018) focused mostly on spatial patterns. Information on the temporal colonization dynamics is, however, important to understand the capacity of $U$. pinnatifida to establish new populations. This study aimed at characterizing the establishment dynamics of $U$. pinnatifida within a newly available artificial site, here a marina, and examining the connectivity between three different population categories (cultivated, established in natural rocky reefs and in marinas), within a bay. Considering the life cycle characteristics and life-history traits of U. pinnatifida (Nyberg, Wallentinius 2005), as well as predictions from a model of the population growth dynamics (Murphy et al. 2016a; Murphy et al. 2017), we hypothesized that the colonization dynamics of the marina should be rapid (i.e., within 1-2 years). Given the limited natural dispersal abilities of $U$. pinnatifida and the role of leisure boating as a dispersal vector at a regional scale (Guzinski et al. 2018), we also hypothesized that the colonization would rely on diverse sources from nearby populations, inside the study bay, as well as from outside the bay.

We chose to test these hypotheses in the bay of Morlaix (Brittany, France), which provides an excellent case study: a farm has been cultivating U. pinnatifida since the end of the 1990's, and natural sites of the bay that were considered as suitable habitats for the establishment of $U$. pinnatifida were surveyed starting the early 2000 s to detect potential spillovers from the seaweed farm. The first population recorded in natural rocky reefs appeared in 2006 (ca. 10 years after the beginning of the farming activities), at a site located nearby the farm (50m). Until 2013, only three other stable populations were reported in rocky reefs. The building of a marina in 2011-2012 in this bay, close to the farm and known rocky reefs populations, gave us the rare opportunity to conduct a real-time monitoring of the colonization in a relatively well-known 
119 historical context of the establishment of this introduced seaweed. We combined field-surveys and a genetic 120 dataset obtained jointly over three years, which correspond to six generations of $U$. pinnatifida in the study area (i.e, two generations per year). Spatio-temporal census data ( $>20000$ individuals geo-localized) as well as spatialized genetic data ( 10 microsatellites loci; $\mathrm{N}=398$ individuals) in the marina allowed us to characterize the colonization patterns (origin of the colonizers, dispersal modes etc.). Temporal genetic data

124 from individuals sampled in the marina and the bay $(\mathrm{N}=816)$ were used to compare the three population categories and their changes over time.

\section{Methods}

\section{Study sites, monitoring and sampling}

The study sites are located in the Bay-of Morlaix (48 $\left.41^{\prime} 46^{\prime \prime} \mathrm{N}, 3^{\circ} 54^{\prime} 18^{\prime \prime} \mathrm{W}\right)$ in Brittany, France (Fig. 1). The building of the marina started in 2011. No Undaria pinnatifida individuals had ever been observed on pilings or breakwater jetties prior to the work, despite intensive survey to record NIS in the context of other research projects (Bouchemousse 2015; FV \& LL, unpublished data). The marina structures include 9 floating pontoons ( $60-205 \mathrm{~m}$ long) linked by a gateway ( 25 sections of $12 \mathrm{~m}$ ), and a floating breakwater of $225 \mathrm{~m}$ ( 9 sections of $25 \mathrm{~m}$ ) protecting the marina at the south (Fig. 1A). Presence of U. pinnatifida on the floating pontoons was checked after their set-up starting in 2012 and detailed monitoring was conducted from 2014 onward following the initial observations. Biannual field surveys (December and March, with an additional survey in February 2014) were used to target separate generations ("Winter" and "Spring") as documented in the study region (Grulois 2010; Murphy et al. 2017; Murphy et al. 2016b; Voisin 2007). The number of individuals per $3 \mathrm{~m}$ long stretches on every artificial structure was recorded, combining diving (for the floating breakwater) and observation from the surface (for the pontoons). Sampling for genetic analyses was carried out during spring surveys: a small piece of tissue ( $2 \times 2 \mathrm{~cm}$ approximatively) was detached from the thalli and stored in silica gel. Until February 2014, all the individuals found in the marina were sampled. After February 2014, because too many individuals were observed, a sub-sampling was done (representative of the spatial distribution and density of the individuals). Each sampled individual was geo-localized, and data integrated in a Geographic Information System (ArcGis). In addition, five nearby natural rocky reefs were surveyed and sampled annually between 2013 and 2015, as well as the farm. The rocky reef populations (Men Guen: MG; Guerhéon: GU; Rannic: RA; Roc'h Velen: RV and Enez Touell: ET; Fig. 1) were sampled (23-36 individuals per site) at low tide or by diving. $U$. pinnatifida was not found in RA and

148 GU in 2014, and populations at two localities were newly recorded during the survey (RV in 2014 and ET in 2015). It is important to note that these observations could be due to survey biases (e.g., timing of the survey of this short lived species, unnoticed individuals at the start of the colonization) rather than true absence or colonization of new sites. Cultivated individuals were sampled on the ropes ( $\mathrm{N}=32-36)$ by diving. 
153 The spatial distribution of individuals in the marina and correlation between abundances of two successive generations were characterized by recording the number of individuals per $3 \mathrm{~m}$-long section (defined by one set of coordinates), then analyzed with bivariate mark correlation functions (second-order statistics, Illian et al. (2008)), using the software Programita (Wiegand, Moloney 2014). To look if pairs of abundances between two successive generations and separated by a distance $r$ were smaller or larger than pairs selected at random, the data were first analyzed with the normalized mark correlation function $k \mathrm{~m}_{\mathrm{i}} \mathrm{m}_{\mathrm{j}}(\mathrm{r})$ :

$$
\operatorname{kmimj}(r)=\frac{m i * m j}{\mu^{2}}
$$

which is the mean of the products of abundance values (counts) $m_{i}$ and $m_{j}$ separated by a distance $r$ divided by the normalization constant $\mu^{2}, \mu$ being the average value over all pairs, $i$ and $j$ being indexes for sets of coordinates belonging to distinct successive generations. The correlation between abundances of successive generations was also investigated using the Schlater's correlation function $I \mathrm{~m}_{\mathrm{i}} \mathrm{m}_{\mathrm{j}}(\mathrm{r})$, which is a Moran's $I$ like summary statistic and a spatial analogous of the Pearson correlation coefficient (Schlather et al. 2004):

$$
\operatorname{Imimj}(r)=\frac{[m i-\mu i(r)] *[m j-\mu j(r)]}{\sigma i \sigma j}
$$
with $\mu_{\mathrm{i}}(\mathrm{r})$ and $\mu_{\mathrm{i}}(\mathrm{r})$ the average of the counts separated by distance $r$ in each successive generation separately and $\sigma_{\mathrm{i}} \sigma_{\mathrm{j}}$. the normalization constant with $\sigma \mathrm{i}^{2}$ and $\sigma \mathrm{j}^{2}$ the variances of the counts in each generation. The observed correlation functions were then compared to global envelopes obtained from 199 Monte-Carlo simulations of the null-model ( $5^{\text {th }}$ lowest and $5^{\text {th }}$ highest values of the estimator, significance level $\alpha=0.05$ ), which consists in randomly shuffling the counts of the second (new) generation but preserving the counts of the first generation as well as the $x$ and $y$ coordinates in each generation. To account for the spatial heterogeneity of the distribution of abundances (e.g., east-west gradient), the counts were shuffled locally within a maximal distance $r$, which preserved the overall heterogeneity ( $\mathrm{r}=25 \mathrm{~m}$ from March 2014 to March 2015, and $\mathrm{r}=50 \mathrm{~m}$ for December 2015 and March 2016). A bandwidth of $6 \mathrm{~m}$ was used when estimating the correlation functions.

\section{DNA extraction and microsatellites genotyping}

177 DNA was extracted with the Nucleospin ${ }^{\circledR} 96$ plant kit (Macherey-Nagel, Düren, Germany), from 3-38 mg 178 of dried tissue, following manufacturer's instructions, but with a modified lysis step at room temperature 179 for one hour instead of $65^{\circ} \mathrm{C}$ for $20 \mathrm{~min}$. Extracted DNA was diluted to 1:100. We chose to use microsatellite 180 markers as a cost-effective technique to examine a large number of individuals. These markers have been 181 shown to provide similar results to ddRad-Sequencing for diversity and connectivity analyses of $U$. 
pinnatifida in the study regions (Guzinski et al. 2018). As compared to ddRad-Sequencing, the use of

183 microsatellites makes also easier the comparison with our previous dataset (Guzinski et al. 2018, Grulois et

184 al. 2011). A total of 816 individuals were genotyped with 10 microsatellite loci, Up-AC-1B2, Up-AC-1B5,

185 Up-AC-1C1, Up-AC-1G2, Up-AC-1H5, Up-AC-2C1, Up-AC-2E8, Up-AC-4G2, Up-AC-4C12, Up-AC-

186 4E9 (Daguin et al. 2005) using multiplex PCRs, as described in Grulois et al. (2011). PCR products were

187 run with a capillary sequencer AB3130XL (Applied Biosystem). Genotypes were scored with GeneMapper

1884.0 (Applied Biosystem). Missing data represented 2.8\% of all data and were distributed across loci and 189 samples.

190 Genetic data analyses

$191 \quad$ Population genetic diversity

192 Genetic diversity indices were estimated for each natural sites and farm samples (detailed in Table S1). For 193 the marina, in 2013 and 2014, all the individuals ( $\mathrm{N}=11$ and 91, respectively) were used as a single sampling 194 unit. For the year 2015, indices were calculated for the individuals sampled over the whole marina $(\mathrm{N}=$ 195 296), as well as over a subsample of 140 individuals, with 30-40 individuals selected from sections S1 and 196 S8 of the breakwater and on pontoons B and I, which were the locations where the highest densities of $U$. pinnatifida were observed in 2014 and thus considered as founding populations. For each sampling unit, we estimated the mean number of alleles per locus $\left(\mathrm{N}_{\mathrm{a}}\right)$, the allelic richness $\left(\mathrm{A}_{\mathrm{r}}\right)$, the observed $\left(\mathrm{H}_{\mathrm{o}}\right)$ and expected heterozygosity under Hardy-Weinberg equilibrium $\left(\mathrm{H}_{\mathrm{e}}\right)$ as well as the $\mathrm{F}_{\text {Is }}$ fixation index, using Genepop v.

2004.3 (Rousset 2008) and Fstat v 2.9.3 (for $\mathrm{A}_{\mathrm{r}}$; Goudet 1995). The null hypothesis of HW equilibrium was 201 tested for each population unit with an exact G-test using Genepop (100 batches of 5000 iterations).

202 Selfing rates and relatedness analyses

203 Undaria pinnatifida being a selfing species (Grulois et al. 2011; Guzinski et al. 2018), selfing rates, s, were 204 estimated from the coefficient $g 2$, computed with the software RMES, and using the equation 9 from (David 205 et al. 2007). The null hypothesis « $g 2=s=0$ » was tested with 1000 random resampling of single-locus 206 heterozygosity between individuals. Because aggregation patterns were observed in the marina (see 207 Results), we hypothesized that related individuals might be found close to each other. A parentage analysis 208 was thus conducted with COLONY 2.0.6.2 (Jones, Wang 2009) on the individuals sampled in 2015. We 209 used the full-likelihood method shown to be the most accurate method (Wang 2012). Other parameters were: 210 presence of inbreeding, no parent-candidates, polygamous mating, medium length run and precision. Each 211 analysis was averaged over 5 runs and conducted twice to evaluate the convergence of the results. Sibship 212 category and selfing were considered as true when the probability was $>0.9$ over the two independent 
213 analyses. We used a one-way ANOVA to test the effect of the Euclidean spatial distances between pairs of 214 individuals on sibship category (full-sib, half-sib and non-related), and differences between categories were 215 assessed with a Tukey HSD test. We finally used the slope $b$ of the regression of the pairwise genetic 216 distance $\hat{a}_{\mathrm{r}}$ and the geographical distance to estimate the axial mean square parent-offspring distance $\left(\sigma^{2}\right)$ 217 (Rousset 2000). The density value used to estimate $\sigma^{2}$ was 0.06 ind. $\mathrm{m}^{-2}$ (4607 individuals counted in Spring 2182015 over an area of ca. $7.5 \times 10^{4} \mathrm{~m}^{2}$ ). The confidence interval at 0.95 was obtained for the slope of the 219 regression with the $\mathrm{ABC}$ bootstrap method implemented in Genepop.

Assignment analyses at the bay scale

221 In order to assess if the sampling sites are connected by recent migration events and determine the most 222 likely origin of the individuals recorded in the marina, we used an assignment procedure, based on the 223 Bayesian method of Rannala and Mountain (1997) implemented in Geneclass v. 2.0 (Piry et al. 2004).

224 Putative sources considered for origin of individuals sampled in 2014 were the populations sampled in 2013. 225 For those sampled in 2015, to account for multi-generational effects, sources were populations sampled in 2262013 and 2014 (i.e., merged genotypic dataset over the two years). The probability of an individual 227 originating from a given putative source was calculated with the method of Paetkau (2004), from 10000 228 Monte-Carlo simulations of individual genotypes and a type I error rate of 0.01 . This probability was used 229 as a threshold to reject $(\mathrm{p}<0.01)$ a putative source and thus take into account non-sampled sources in the 230 analysis (i.e., exclusion of all the studied putative sources).

\section{Genetic structure at the bay and marina scale}

232 Genetic differences were examined by computing the estimator $\theta$ of $\mathrm{F}_{\mathrm{ST}}$ (Weir, Cockerham 1984). The null 233 hypothesis that alleles are drawn from the same distribution in all populations was tested with a G-test in 234 Genepop. We used the Bayesian clustering method implemented in InStruct v. 1. 0 to account for selfing 235 (Gao et al. 2007). In this approach, the most likely number $\mathrm{K}$ of clusters is assessed with a model that does 236 not assume Hardy-Weinberg equilibrium within cluster: the cluster of origin of individuals (with potential 237 admixture) and the individual's inbreeding coefficients are jointly estimated. The number of MCMC 238 iterations was set at 250000 , with a burn-in of 50000 and a thinning of 10 (i.e., 2000 saved iterations). We 239 ran the program for 10 independent chains with values of $\mathrm{K}$ between 1 and 20. The Deviance Information 240 Criterion (DIC) was plotted against $K$ to select the best $K_{\max }$ (Gao et al. 2011).

241 To characterize the spatial distribution of discrete genetic groups in the population established over the 242 marina in 2015, we combined the Bayesian clustering methods implemented in Instruct and in the R library 243 Geneland v.4.0.5 (Guillot et al. 2005a; Guillot et al. 2005b). We first determined the best number of clusters 
explaining the overall genetic distribution using Instruct v. 1. 0 , with values of $\mathrm{K}$ between 1 and 16 . We then ran Geneland, with the best $\mathrm{K}$ estimated from Instruct, to assess the spatial distribution of the $\mathrm{K}$ genetic clusters, using a model with correlated allele frequencies, an uncertainty of the coordinate of 0.5 (accounting for the presence of individuals with identical coordinates) and potential null alleles. The number of MCMC iterations was set at 250000 , with a thinning of 100 . For the post-processing of the output, the spatial domain was defined with $\mathrm{X}=100$ et $\mathrm{Y}=150$ and the burn-in was 500 . The results of 5 independent runs were compared to assess the correspondence of the spatial clusters.

\section{Results}

\section{Colonization dynamics of the marina}

The survey started in 2012 but Undaria pinnatifida did not appear in the marina until February 2013, when a first group of individuals ( $\mathrm{N}=11$, all mature) were found on the hull of a leisure boat located at the east end of the pontoon I (Fig. 1, Fig. 2). The colonization started the year after mainly on the floating breakwater (Fig. 2, February 2014), though three individuals were also observed on pontoons F and I. Over time, empty spots on the breakwater were gradually colonized (Fig. 2, March 2014-March 2016). For pontoons, the colonization really started with the next winter generation (December 2014; Fig. 2), moving from the eastern side (extremity) towards the western side (inside) of each pontoon. In 2016, the marina was fully colonized (Fig. 2, March 2016).

Concomitantly to the spatial expansion, the densities increased over successive generations between March 2014 and March 2016 (Fig. 2, Supplementary Material Fig. S1). In March 2016, densities reached 1 ind. $\mathrm{m}^{-1}$ at the whole marina scale (8117 $\mathrm{m}$ of available substrate, with $>9200$ individuals counted overall). Locally, the density reached much higher values: 12,18 and 50 ind. $\mathrm{m}^{-1}$ found on the gateway, floating pontoons and breakwater respectively (Fig. 2). Population growth followed different trends according to the location within the marina (Fig. S1): on the gateway and along the pontoons the best fit was with an exponential growth curve (Fig. S1C-D) whereas it follows a logarithmic growth curve on the breakwater (Fig. S1B).

The mark-correlation functions analyses revealed a clustering pattern of the number of individuals between two consecutive surveys, with the size of the clusters increasing with time. Abundances of individuals observed nearby groups of the previous generation were significantly larger than for pairs of groups selected at random (Fig. 3 B-D-F-H). The spatial extent of this relationship increased over time (0$2 \mathrm{~m}$ for March-December 2014 to 0-22m for December 2015-March 2016). Moderate to high positive correlations were found for pairs of groups from two consecutive generations located below $24 \mathrm{~m}$ (Fig. 3A- 
C-E-G). On the contrary, at greater distances, pairs of abundances from groups of two successive generations tend to be smaller or equal to pairs chosen randomly, and negatively or not correlated.

\section{$277 \quad$ Genetic diversity in the study samples}

278 Regardless of the year and the population category (i.e., marina, farm, rocky reefs), all the study populations were found to be polymorphic, including the set of 11 individuals collected on the ship hull in 2013, which, despite its small census size, show the highest allelic richness (2.7; Table 1). The lowest allelic richness estimates were observed in the cultivated population (1.5 in 2014 and 2015) and in one rocky reef (MG; 1.3 to 1.7 across years; Supplementary Material Table S1). Similar results were found for the expected genetic diversity $\left(\mathrm{H}_{\mathrm{e}}\right.$; Table 1, Table $\left.\mathrm{S} 1\right)$. Altogether, the marina population showed equal or higher genetic diversity than populations sampled in natural rocky reefs, the latter being (with the exception of MG) more genetically diverse than the farm. Ten out of the 19 study populations display significant deviations from expectations under the Hardy-Weinberg equilibrium, all from the marina or wild sites (Table 1, Table S1). These heterozygote deficiencies are likely due to selfing, which is were clearly evidenced in 7 out of these 10 populations based on the g2 statistics. Selfing rates varied over time in the marina, null in the colonizing population (2014) but reaching $36 \%$ in 2015 .

\section{Genetic structure at the bay scale and origin of the colonizers in the marina}

291 High and significant genetic structure was observed at the bay scale, with $\mathrm{F}_{\mathrm{ST}}$ values of $0.33\left(\mathrm{p}<10^{-5}\right), 0.30$

$292\left(\mathrm{p}<10^{-5}\right)$ and $0.16\left(\mathrm{p}<10^{-5}\right)$ in 2013, 2014 and 2015, respectively. Bayesian clustering analyses (InStruct) showed that the overall genetic variation found in the bay (19 sampling units sampled between 2013 and 2015, N= 658 individuals) was best explained by four genetic clusters (K=4; Fig. 4). Individuals collected on pontoons and breakwater showed higher membership to two clusters, pictured in yellow and orange in

296 Fig. 4. Many individuals of pontoon B and breakwater section S1 showed membership to the yellow cluster also characteristic of the individuals from the natural sites RV, ET and RA. Conversely, pontoon I and breakwater section S8, showed high membership to the orange cluster mostly found in rocky reef-GU in 2013 (but not in 2015). One rocky reef, MG, displayed a very distinctive genetic background pictured by

300 the purple color in Fig. 4. The farm was also clearly differentiated in 2014 and 2015 (blue color, Fig. 4) but 301 shared membership with the marina and rocky reef-GU in 2013 (orange cluster). The two well established rocky reef populations MG and RA showed a stable genetic background throughout the sampling period.

303 Inspecting results for lower and higher $\mathrm{K}$-values $(\mathrm{K}=3, \mathrm{~K}=5)$ confirmed the main patterns, with $\mathrm{MG}$ and the farm (in 2014 and 2015) well differentiated from all the other samples (Supplementary Material, Fig. S2). 
InStruct results were confirmed with the assignment analyses carried at the bay scale (Fig. 5). In the marina, the first wave of settlers (February 2014, N =91) were assigned to different sources, with diverse contributions (Fig. 5A). Almost half of the individuals (48\%) were assigned to the rocky reef GU, the geographically closest natural population, whereas $12 \%$ seem to originate from the reproduction of the mature sporophytes observed in 2013 on the hull of a boat. A small proportion (9\%) could not be assigned to any of the sampled populations, pointing to unknown sources. In 2015, an important change was observed, as most of the individuals (44\%) were assigned to the marina population samples of 2013-2014 (Fig. 5B). For the rocky reef MG, almost all the individuals were assigned to the same locality sampled in the previous years (97\% for 2014 and $100 \%$ for 2015; Fig. 5A-B). For the two sites where putative extinction-recolonization occurred (rocky reefs RA and GU), different patterns were observed (Fig. 5B): diverse sources contributed to GU in 2015, whereas RA individuals were mostly assigned to the population found at the same site in 2013. For GU, most of the individuals (68\%) were assigned to the nearby located farm. For the putatively new rocky reef populations, RV and ET, the first individuals were assigned to diverse sources. In RV, the largest proportion (32\%) of the individuals sampled in 2014 could not be assigned to any of the putative sources sampled in 2013, but the year after, most individuals of RV were assigned to the same site (75\% of R15-RV individuals assigned to R14-RV). For ET, newly reported in $2015,26 \%$ of the individuals were assigned to the marina.

\section{Spatial and kin aggregation in the marina}

Five genetic clusters best explained the genetic variation of the 296 individuals sampled in the marina in 2015. Each of these five clusters display a clear spatial aggregation pattern (Fig. 6): individuals belonging to the same genetic group are clumped into relatively high density "nuclei" spread over a small area (mean distance between individuals forming a nucleus: $17.5 \pm 14.9 \mathrm{~m})$. The most extreme situation was found with the fifth genetic cluster (Fig. 6F), composed of only 7 individuals, all grouped very closely at the eastern extremity of pontoons $\mathrm{F}$ and H. Six of them are full-sibs (see below) and were among the individuals excluded from all the putative sampled sources. For the four other clusters, $8 \%$ of the individuals were located farther away from their nuclei in the marina suggesting longer-distance dispersal events $(\sim 80-320 \mathrm{~m})$.

Analyses with COLONY revealed 13 lineages of full-sibs, representing 12\% of the 296 sampled individuals. Five lineages were pairs of individuals produced by outcrossing and the other eight ( 5 pairs and 3 groups of 4-6 individuals) were produced by independent selfing events. In addition, a complex half-sib structure was found, with 26 individuals related to one or more individuals. This kinship structure was aggregated in space (Supplementary Material, Fig. S3). Interestingly, the mean Euclidian distances between pairs of individuals decreased inversely to the level of kinship, from unrelated (131.6 $\pm 77.9 \mathrm{~m})$ to half-sibs 
$337(60.1 \pm 63.7 \mathrm{~m})$ down to full-sibs $(16.6 \pm 34.4 \mathrm{~m})$ (Fig. S4). This is congruent with the axial mean parent-

338 offspring distance $\left(\sigma^{2}\right)$ estimated to $6.8 \mathrm{~m}$ (with a population density $D$ of 0.06 ind. $\mathrm{m}^{-2}$ ).

\section{Discussion}

340 Temporal studies of marine invasive species have long been recognized of paramount importance to 341 understand invasion processes (Strayer et al. 2006), as exemplified in the few available temporal genetic 342 studies of marine invaders (e.g., Goldstien et al. (2013) and references therein). Temporal demo-genetic 343 surveys can reveal new introductions, clarify the processes by which introduced species establish 344 sustainably (i.e., immigration vs. local reproduction) and identify sources for the colonization of new 345 habitats. This study illustrates such outcomes in the invasive seaweed Undaria pinnatifida. We showed that 346 1) the colonization of the newly-built marina was fast, 2) the initial sources were multiple, including leisure 347 boats, rocky reefs, and cultivated populations; 3) the origin of the successive generations shifted over time 348 in the marina, with populations becoming self-sustaining; a process also observed in putatively newly 349 colonized natural rocky reefs.

\section{A snow-ball colonization dynamics}

351 The first report of the presence of $U$. pinnatifida in the newly built marina were mature sporophytes on the 352 hull of a boat in February 2013, but no individuals were recorded on the floating pontoons and breakwater 353 before February 2014. There was thus a time lag of at least one year and a half between the setting-up of 354 the floating pontoons (June 2012) and the presence of the first sporophytes on these artificial structures, 355 even though farmed populations and rocky reefs populations (RA, GU and MG) were present in the vicinity 356 in 2011 and 2012. This lag could be explained by the requirement of a minimal density of spore settlement 357 and gametophytes, which is needed for the successful fertilization and production of sporophytes (Reed 358 1990). Increased propagule pressure and/or germination of dormant gametophytes (Hoffmann, Santelices 359 1991; Saito 1975a) could explain the sudden establishment observed in February 2014. U. pinnatifida then 360 quickly colonized the available structures resulting in very high abundances ( $>9000$ individuals) after only 361 two years (5 generations). The growth curves (Fig. S1) illustrate this snowball effect. The densities observed 362 in the marina of Bloscon at the end of this study are similar to what have been observed in other marinas in 363 the English Channel (Epstein, Smale 2018a; Epstein, Smale 2018b; Murphy et al. 2016b).

A series of life-history traits, including a short life cycle, high fecundity, ability to self, are likely major factors enabling U. pinnatifida to quickly colonize available space (Nyberg, Wallentinius 2005). In addition, this kelp also probably benefits from reduced competitive abilities and niche dissimilarities in marinas, notably with native kelps (Bulleri, Chapman 2010; De Leij et al. 2017; Epstein et al. 2019; Farrell et al. 2006). The gametophytes of U. pinnatifida have the ability to stay dormant during several months 
369 (Hoffmann, Santelices 1991; Saito 1975a) and to emerge as soon as the environmental conditions are 370 favorable. This "seed bank", combined with the rapid growth of U. pinnatifida, could result in a priority

371 effect compared to species which emerge later in the season or have a slower growth (Collinge, Ray 2009;

372 Dickson et al. 2012). The rapid increase of abundance and quick spread over the marina within a two-year 373 period confirm the status of $U$. pinnatifida as a pioneer species (Nyberg, Wallentinius 2005), particularly in 374 anthropogenic habitats.

Local spread results from a combination of gradual and jump dispersal likely modulated by environmental filters

The colonization of the marina presumably results from a mixed-mode of spread, in which primary long-distance saltatory events are followed by gradual dispersal over short distances, producing clumps of individuals. A few long-distance dispersal events (> 100m; i.e., jump dispersal) were evidenced by both the landscape genetic (Geneland, Fig. 6) and the mark-correlation analyses (Fig. 3). Such saltatory dispersal could be due to drifting thalli detached from their substrate, for example during the cleaning of the marina infrastructures (Guzinski et al. 2018; Sliwa et al. 2006; South et al. 2017). In contrast, the gradual dispersal at short distance is most likely explained by spore and gamete dispersal. The field surveys (Fig. 2) and the mark-correlation analysis (Fig.3) indicate an increase in density where individuals of the previous generation were observed. Interestingly, the population established in 2015 displayed substantial selfing rates as compared to the previous year. Together with the clustering of genetically similar individuals over short distance (typically below $25 \mathrm{~m}$ ), this suggests that selfing sustains the gradual colonization and establishment in this habitat.

The mixed-mode of dispersal likely explains the erratic spatial pattern of colonization observed over time at the marina scale. However, locally (along pontoons or breakwater), directional spread was observed, and might be due to other factors, notably environmental factors. The first individuals found in March 2014 appeared on the breakwater, with $90 \%$ of them located on the southern side of the breakwater (i.e., external side of the marina). The southern side is more exposed to currents and wave motion, but also to a stronger propagule pressure (released from other sites within the bay) which increases the chance of spore settlement.

396 In addition, the southern site is more exposed to incident light, a major environmental factor controlling population growth of $U$. pinnatifida (see Murphy et al. (2017) and references therein). Similarly, inside the marina, a density gradient differentiates the eastern from the western sides of the pontoons. A potential explanatory factor is water motion known to benefit to this seaweed (Peteiro et al. 2016). Current velocities have not been measured, but are known to be higher in the eastern ("outer") than in the western ("inner") part of the marina due to its configuration, widely opened to tidal currents (Fig. 1). Reduced mixing of the 
water occurring in the western side of the marina could also result in lower abundance of nutrients, which can affect negatively the growth of $U$. pinnatifida (Morelissen et al. 2013). Environmental factors determining the heterogeneous pattern of colonization in the marina of Bloscon will require further dedicated experimental studies. However, it is noteworthy that the population dynamics observed in Bloscon was overall qualitatively similar to the outcomes of an agent-based modelling study of the population growth of $U$. pinnatifida, which highlighted the importance of abiotic factors, notably light availability (Murphy et al. 2016a; Murphy et al. 2017).

\section{Spill-back effects are followed by a shift towards a self-sustaining population}

Genetic assignment showed that the first colonizers of the breakwater and floating pontoons in 2014 originated from multiple sources, and mainly from rocky reefs populations located at least $1 \mathrm{~km}$ away. The role of the rocky reef populations as a primary source of colonizers in a new anthropogenic habitat was somewhat unexpected. Marinas and farms have been targeted as sources of new populations in the wild (i.e., spillover events, (Epstein, Smale 2018b; Guzinski et al. 2018; James, Shears 2016). The present study shows that, reciprocally, natural populations can act as sources toward newly built artificial sites (i.e., spillback event).

Immigration, from farms or rocky reefs, could result from the transport of spores by water currents, from drifting thalli detached from their substrate by storms or human activities (Sliwa et al. 2006), or by recreational vessels (South et al. 2017, Ulman et al. 2019). Although spores only remain viable for a short period of time (1-2 days, Saito (1975a)), the high speed tidal currents in the bay of Morlaix, particularly during spring tides (up to $0.75 \mathrm{~m} / \mathrm{s}$ in the vicinity of the marina), could carry spores and drifting thalli from nearby rocky reefs to the marina. The role of recreational boating should however not be neglected: it has been proposed to explain the colonization of marinas in England by U. pinnatifida (Fletcher, Farrell 1999), and regional chaotic genetic structure reported in the study region Brittany (Guzinski et al. 2018). Mature sporophytes and most likely gametophytes can indeed attach to the hull of leisure boats, ropes and buoys (Bollen et al. 2017; South et al. 2017). In addition, mature sporophytes were observed on the hull of several leisure boats in the marina during the survey (pers. observation). In this context, it is noteworthy that $12 \%$ of the colonizers of the marina in 2014 were assigned to the mature sporophytes collected on the hull of a boat the previous year. We can hypothesize that the individuals excluded from all sampled populations in assignment tests might originate from other bays, after their transport by leisure boats infested by the seaweed and moored (but not sampled) in the study marina. This pathway could notably explain the assignment of the group of 6 individuals from 2015 to unknown sources and isolated in a distinct genetic cluster (Fig. 6) and identified as full-sibs (Fig. S3). 
An important outcome of our temporal genetic survey is to document a major change of the parental 435 (source) population over time. Indeed, conversely to the previous year, in 2015, almost half the individuals 436 were assigned to the population sampled in the marina in 2013-2014, showing that the population shifted toward self-sustaining (Fig. 5B). This could be explained by a priority effect (Fraser et al. 2015) at the intraspecific level, whereby the early growth of locally produced sporophytes at high density could prevent the recruitment of new Undaria immigrants arriving later in the season. In addition, selfing, which is reaching $36 \%$ in this established population (Table 1) can accentuate this effect through rapid space monopolization, as shown by the short dispersal distance between full-sibs $(<20 \mathrm{~m})$. This local recruitment could have occurred from the presence of dormant gametophytes and/or reproduction of overwintering mature sporophytes (Epstein, Smale 2018a). Dormancy in gametophytes of kelps usually do not exceed a few months (Hoffmann, Santelices 1991), but data on the maximum extent of dormancy in Undaria gametophytes is lacking.

\section{From spill-back to spill-over events at the bay scale}

Two populations were recorded for the first time at new rocky reefs sites during this study (RV and ET). It cannot be ascertained with confidence if they were truly absent in the previous years or were simply unnoticed because of the complexity of the rocky shore landscape, especially if the founding population was small. However, the genetic data support the first scenario (i.e., new colonization), in comparison to what have been observed in the marina. The rocky reef populations RV and ET indeed displayed assignment to multiple sources the first year of report. In addition, the source of new recruits quickly shifted to withinsite reproduction in RV over the two years of survey (Fig. 5A-B), as also observed in the marina. In contrast, well-established rocky reef populations, such as MG or RA, reported for a long time, showed a high stability in the genetic time series, with self-recruitment being the dominant source of individuals at these sites. Note that this pattern actually makes the presumed absence of RA in 2014 highly doubtful, rather suggesting that this population was present the year before, although not observed (and thus not sampled). The temporal stability of the genetic background documented here is congruent with results from other studies (e.g., over ten years in St-Malo Bay, Guzinski et al. (2018)). It suggests that priority effects are present both in artificial and natural habitats. To which extent self-sustaining populations may evolve local adaptation is unknown. However, for the rocky reef population MG, a genome scan analysis found loci putatively under selection or linked with markers under selection in the population sampled in 2015 (Guzinski et al. 2018).

It is noteworthy that the marina contributed substantially to the colonization of both rocky reef populations RV and ET, showing spill-over events from marinas to the wild, as hypothesized in previous studies (Epstein, Smale 2018b; Guzinski et al. 2018). More generally, except MG, all the rocky reef populations studied in 2015 show some assignment to the marina. The capacity of $U$. pinnatifida to build 
up very high densities in artificial habitats makes the marina a potential important source of propagules to natural rocky reefs of the bay, after only two years since the first colonization. This observation is particularly interesting considering that the colonization of wild habitats by $U$. pinnatifida has been slow in the bay of Morlaix, with the first wild population recorded in GU in 2006 (ca. 10 years after the beginning of the culture of this kelp) even though GU and the farm are separated by only $50 \mathrm{~m}$. In comparison, the Bay of St. Malo in Brittany was already heavily colonized 10 years after the set-up of a farm (Castric-Fey et al. 1993; Girard-Descatoire et al. 1997). Besides competition with native seaweeds, particularly perennial kelps, which may decrease the establishment success of $U$. pinnatifida in the study region (Epstein et al. 2019; Epstein, Smale 2018b), the lag time observed in the Bay of Morlaix could be explained by an initial low propagule pressure, in the absence of a marina where particularly high density of $U$. pinnatifida are reported (this study; Epstein, Smale 2018a).

With the presence of $U$. pinnatifida at high density in the newly built marina, one could hypothesize a rapid spread at the bay level, which was actually evidenced by a survey carried out in April 2019 by two of us (FV, LL). As compared to the situation examined in this study, novel populations were reported in the wild, together with an expansion in the port area (i.e., beyond the marina, including concrete substrates such as the ferry jetty). An almost continuous presence of $U$. pinnatifida on all favorable rocky substrates, located in the south of the marina, is now observed. This Pacific kelp is now present (and expands) in the south, the north and the west of the study bay (Supplementary material, Fig. S5). Abundances of U. pinnatifida in these natural sites are usually ca. two orders of magnitude lower than in the marina. However, in some sites, the densities are comparable to those of native kelp species, notably in the putatively recently established populations RV and ET, allowing for commercial harvesting of the thalli of this edible alga by local people (as suggested by dozens of specimens cut above the sporophylles observed during the 2019 survey). The combination of the increased propagule pressure and spill-over from the marina with the ability to $U$. pinnatifida populations to be rapidly self-sustaining are responsible for the (likely) sustainable establishment of the species at the bay scale.

This study is a new evidence supporting the need for careful management of marinas to prevent spread of non-native species into the wild. The evaluation of these risks should be better integrated into Environmental Impacts Assessments (EIA) prior to building new infrastructures. In particular, the NIS already reported in nearby natural rocky habitats should be listed and particularly scrutinized, as they are at risk of colonizing the newly built infrastructure, as exemplified here with U. pinnatifida. Areas at high risk 498 (e.g., according to shipping intensity; Shucksmith and Shelmerdine 2015). As advocated in other studies 499 (e.g., Ulman et al. 2019; Epstein, Smale 2017; Peters et al. 2019), our results and surveys call for 
standardized monitoring and surveillance protocol of NIS in marinas, including the hull of recreational vessels, neglected for a long time. Importantly, for those species, such as $U$. pinnatifida, characterized by rapid population growth, strong monitoring efforts and early response are certainly critical. We indeed showed a snow-ball colonization dynamics and high abundance after only 2 years, that may complicate or even prevent its control and eradication. For instance, Forrest \& Hopkins (2013) showed that sustained control (i.e., monthly hand removal on any visible substrates and hulls) is needed to substantially decreased the number of boats infested by U. pinnatifida while partial control (i.e., removal targeted over a short time period) resulted in a number of infested boats similar to non-managed marinas. However, even if the species has colonized the marina, one should not neglect management options aiming at decreasing the propagule pressure, by reducing the density and abundance on both the marina infrastructures and leisure boats: reducing the propagule pressure may help in limiting the rapid colonization in nearby sites, particularly in rocky reefs where native species can slow-down the establishment of the NIS through competitive interactions (Epstein and Smale 2018b). Another facet of the present work was to show that many Undaria populations are inconspicuous. Considerable monitoring efforts were needed to localize the populations established in rocky reefs because of the complexity of the landscape and location of suitable habitats, which are not easily accessible at low tide and require diving. Nonetheless, a reliable and accurate spatio-temporal mapping is needed to determine high-risks areas. Recently, Jeunen et al. (2019) showed that U. pinnatifida presence could be recovered by COI metabarcoding. Such an approach based on environmental DNA is promising to detect this Pacific kelp as well as other hidden NIS.

\section{References}

Airoldi L, Turon X, Perkol-Finkel S, et al. (2015) Corridors for aliens but not for natives: effects of marine urban sprawl at a regional scale. Divers Distrib 21:755-768

Bishop J, Wood CA, Lévêque L, et al. (2015) Repeated rapid assessment surveys reveal contrasting trends in occupancy of marinas by non-indigenous species on opposite sides of the western English Channel. Mar Pollut Bull 95:699-706

Bollen M, Battershill CN, Pilditch CA, et al. (2017) Desiccation tolerance of different life stages of the invasive marine kelp Undaria pinnatifida: Potential for overland transport as invasion vector. J Exp Mar Biol Ecol. 496:1-8

Bouchemousse S (2015) Dynamique éco-évolutive de deux ascidies congénériques et interferiles, l'une indigène et l'autre introduite, dans leur zone de sympatrie. Doctoral thesis. Université Pierre \& Marie Curie (Paris 6). https://tel.archives-ouvertes.fr/tel-01337034 
Bulleri F, Chapman MG (2010) The introduction of coastal infrastructure as a driver of change in marine environments. J Appl Ecol 47:26-35

Castric-Fey A, Girard A, L'Hardy-Halos MT (1993) The distribution of Undaria pinnatifida (Phaeophyceae, Laminariales) on the coast of St Malo (Brittany, France). Bot Mar 36:351-358

Clarke Murray C, Pakhomov EA, Therriault TW (2011) Recreational boating: a large unregulated vector transporting marine invasive species. Divers Distrib 17:1161-1172

Collinge SK, Ray CJE (2009) Transient patterns in the assembly of vernal pool plant communities. Ecology 90:3313-3323

Daguin C, Voisin M, Engel C, et al. (2005) Microsatellites isolation and polymorphism in introduced populations of the cultivated seaweed Undaria pinnatifida (Phaeophyceae, Laminariales). Conserv Genet 6:647-650

David P, Pujol B, Viard F, et al. (2007) Reliable selfing rate estimates from imperfect population genetic data. Mol Ecol 16:2474-2487

De Leij R, Epstein G, Brown MP, et al. (2017) The influence of native macroalgal canopies on the distribution and abundance of the non-native kelp Undaria pinnatifida in natural reef habitats. Mar Biol 164:156

Dickson TL, Hopwood JL, Wilsey BJJBI (2012) Do priority effects benefit invasive plants more than native plants? An experiment with six grassland species. Biol Invasions 14:2617-2624

Duarte CM, Pitt KA, Lucas CH, et al. (2013) Is global ocean sprawl a cause of jellyfish blooms? Front Ecol Environ 11:91-97

Epstein G, Hawkins SJ, Smale DA (2019) Identifying niche and fitness dissimilarities in invaded marine macroalgal canopies within the context of contemporary coexistence theory. Sci Rep-UK 9:8816

Epstein G, Smale DA (2017) Undaria pinnatifida: A case study to highlight challenges in marine invasion ecology and management. Ecol Evol 7:8624-8642

Epstein G, Smale DA (2018a) Between-habitat variability in the population dynamics of a global marine invader may drive management uncertainty. Mar Pollut Bull 137:488-500

Epstein G, Smale DA (2018b) Environmental and ecological factors influencing the spillover of the nonnative kelp, Undaria pinnatifida, from marinas into natural rocky reef communities. Biol Invasions 20:1049-1072

Farrell P, Fletcher RJ (2006) An investigation of dispersal of the introduced brown alga Undaria pinnatifida (Harvey) Suringar and its competition with some species on the man-made structures of Torquay Marina (Devon, UK). J Exp Mar Biol Ecol. 334:236-243

Firth LB, Knights AM, Bridger D et al. (2016). Ocean sprawl: challenges and opportunities for biodiversity management in a changing world. Oceanogr Mar Biol 54: 193-269. 
Fletcher RL, Farrell P (1999) Introduced brown algae in the North East Atlantic, with particular respect to Undaria pinnatifida (Harvay) Suringar. Helgolander Meeresun 52:259-275

Floc'h J-Y, Pajot R, Mouret V (1996) Undaria pinnatifida (Laminariales, phaeophyta) 12 years after its introduction into the Atlantic ocean. Hydrobiologia 326/327:217-222

Forrest BM, Brown SN, Taylor MD, et al. (2000) The role natural dispersal mechanisms in the spread of Undaria pinnatifida (Laminariales, Phaeophyceae). Phycologia 39:547-553

Forrest B, Hopkins G (2013). Population control to mitigate the spread of marine pests: insights from management of the Asian kelp Undaria pinnatifida and colonial ascidian Didemnum vexillum. Manag Biol Invasions 4: 317-326.

Fraser CI, Banks SC, Waters JM (2015) Priority effects can lead to underestimation of dispersal and invasion potential. Biol Invasions 17:1-8

Gao H, Bryc K, Bustamante CD (2011) On identifying the optimal number of population clusters via the deviance information criterion. PLOS ONE 6:e21014

Gao H, Williamson S, Bustamante CD (2007) A Marko Chain Monte Carlo approach for joint inference of population structure and inbreeding rates from multi-locus genotype data. Genetics 76:1635-1651

Girard-Descatoire A, Castric-Fey A, L'Hardy-Halos M (1997) Inventaire de la faune et de la flore sur les fonds rocheux de Saint-Malo et de Dinard. Report for Direction Régionale de l'Environnement Bretagne, Conseil Régional de Bretagne. Rennes

Glasby T, Connell S, Holloway M, et al. (2007) Nonindigenous biota on artificial structures: could habitat creation facilitate biological invasions? Mar Biol 151:887-895

Goldstien SJ, Inglis GJ, Schiel DR, et al. (2013) Using temporal sampling to improve attribution of source populations for invasive species. PLOS ONE 8

Goudet J (1995) Fstat (version 1.2): a computer program to calculate F-statistics. J Hered 86:485-486

Grulois D (2010) Etude de la dispersion et du recrutement à différentes échelles spatiales chez Undaria pinnatifida, une macro-algue brune introduite le long des côtes bretonnes. Doctoral Thesis. Université Pierre et Marie Curie (Paris 6). https://hal.sorbonne-universite.fr/tel-01111061.

Grulois D, Leveque L, Viard F (2011) Mosaic genetic structure and sustainable establishment of the invasive kelp Undaria pinnatifida within a bay (Bay of St-Malo, Brittany). Cah Biol Mar 52:485498

Guillot G, Estoup A, Mortier F, et al. (2005a) A spatial statistical model for landscape genetics. Genetics $170: 1261-1280$

Guillot G, Mortier G, Estoup A (2005b) Geneland: A computer package for landscape genetics. Mol Ecol Notes 5:708-711 
Guzinski J, Ballenghien M, Daguin-Thiébaut C, et al. (2018) Population genomics of the introduced and cultivated Pacific kelp Undaria pinnatifida: Marinas—not farms — drive regional connectivity and establishment in natural rocky reefs. Evol Appl 11:1582-1597

Hoffmann AJ, Santelices BJMepsO (1991) Banks of algal microscopic forms: hypotheses on their functioning and comparisons with seed banks. Mar Ecol-Prog Ser 79:185-194

Illian J, Penttinen A, Stoyan H, et al. (2008) Statistical analysis and modelling of spatial point patterns. John Wiley \& Sons

James K, Shears NT (2016) Proliferation of the invasive kelp Undaria pinnatifida at aquaculture sites promotes spread to coastal reefs. Mar Biol 163:1-12

Jeunen G-J, Knapp M, Spencer HG, et al. (2019) Environmental DNA (eDNA) metabarcoding reveals strong discrimination among diverse marine habitats connected by water movement. Mol Ecol Resour 19:426-438

Jones O, Wang J (2009) COLONY: a program for parentage and sibship inference from multilocus genotype data. Mol Ecol Resour 10:551-555

Lodge DM, Simonin PW, Burgiel SW, et al. (2016) Risk analysis and bioeconomics of invasive species to inform policy and management. Annual Review of Environment and Resources 41:453-488

Mineur F, Johnson M, Maggs C (2008). Macroalgal introductions by hull fouling on recreational vessels: seaweeds and sailors. Environ Manage 42: 667-676.

Morelissen B, Dudley BD, Geange SW, et al. (2013) Gametophyte reproduction and development of Undaria pinnatifida under varied nutrient and irradiance conditions. J Exp Mar Biol Ecol 448:197206

Murphy JT, Johnson MP, Viard F (2016a) A modelling approach to explore the critical environmental parameters influencing the growth and establishment of the invasive seaweed Undaria pinnatifida in Europe. J Theor Biol 396:105-115

Murphy JT, Johnson MP, Viard F (2017) A theoretical examination of environmental effects on the life cycle schedule and range limits of the invasive seaweed Undaria pinnatifida. Biol Invasions 19:691-702

Murphy JT, Voisin M, Johnson M, et al. (2016b) Abundance and recruitment data for Undaria pinnatifida in Brest harbour, France: Model versus field results. Data in Brief 7:540-5

Nyberg CD, Wallentinius I (2005) Can species traits be used to predict marine macroalgal introductions? Biol Invasions 7:265-279

Ojaveer H, Galil BS, Campbell ML, et al. (2015) Classification of non-indigenous species based on their impacts: Considerations for application in marine management. PloS Biol 13:e1002130 
Paetkau D, Slade R, Burden M, et al. (2004) Genetic assignment methods for the direct, real-time estimation of migration rate: a simulation-based exploration of accuracy and power. Mol Ecol 13:55-65

Peteiro C, Sánchez N, Martínez B (2016) Mariculture of the Asian kelp Undaria pinnatifida and the native kelp Saccharina latissima along the Atlantic coast of Southern Europe: An overview. Algal Research 15:9-23

Peters K, Sink KJ, Robinson TB (2019). Sampling methods and approaches to inform standardized detection of marine alien fouling species on recreational vessels. J Environ Manage 230: 159-167.

Piry S, Alapetite A, Cornuet J-M, et al. (2004) GeneClass2: a software for genetic assignment and first generation migrants detection. J Hered 95:536-539

Pyšek P, Richardson DM (2010) Invasive species, environmental change and management, and health. Annual Review of Environment and Resources 35:25-55

Rannala B, Mountain JL (1997) Detecting immigration by using multilocus genotypes. Proc Natl Acad Sci USA 94:9197-9201

Reed DC (1990) The effects of variable settlement and early competition on patterns of kelp recruitment. Ecology 71:776-787

Rius M, Turon X, Bernard G, et al. (2015) Marine invasion genetics: from spatial and temporal patterns to evolutionary outcomes. Biol Invasions 17:869-885

Rousset F (2000) Genetic differentiation between individuals. J Evol Biol 13

Rousset F (2008) Genepop'007: a complete re-implementation of the genepop software for Windows and Linux. Mol Ecol Resour 8:103-106

Saito Y (1975a) Practical significance of algae in Japan: Undaria. Advance of Phycology in Japan:304320

Saito Y (1975b) Undaria. In: Tokida J and Hirose H (eds) Advance in phycology in Japan. Junk publishers., The Hague, pp. 304-320

Schlather M, Ribeiro Jr PJ, Diggle PJ (2004) Detecting dependence between marks and locations of marked point processes. J R Stat Soc B 66:79-93

Shucksmith RJ, Shelmerdine RL (2015). A risk based approach to non-native species management and biosecurity planning. Mar Policy 59: 32-43.

Simberloff D, Martin J-L, Genovesi P, et al. (2013) Impacts of biological invasions: what's what and the way forward. Trends Ecol Evol 28:58-66

Sliwa C, Johnson CR, Hewitt CL (2006) Mesoscale dispersal of the introduced kelp Undaria pinnatifida attached to unstable substrata. Bot Mar 49:396-405 
665

666

667

668

669

670

671

672

673

674

675

676

677

678

679

680

681

682

683

684

685

South PM, Floerl O, Forrest BM, et al. (2017) A review of three decades of research on the invasive kelp Undaria pinnatifida in Australasia: An assessment of its success, impacts and status as one of the world's worst invaders. Mar Environ Res 131:243-257

South PM, Thomsen MS (2016) The ecological role of invading Undaria pinnatifida: an experimental test of the driver-passenger models. Mar Biol 163

Strayer DL, Eviner VT, Jeschke JM, et al. (2006) Understanding the long-term effects of species invasions. Trends Ecol Evol 21:646-651

Ulman, A, Ferrario, J, Forcada, A, et al. (2019) Alien species spreading via biofouling on recreational vessels in the Mediterranean Sea. J Appl Ecol. 00: 1- 10. (Early View)

Voisin M (2007) Les processus d'invasions biologiques en milieu côtier marin :le cas de l'algue brune Undaria pinnatifida, cultivée et introduite à l'échelle mondiale. Doctoral Thesis. Université Pierre \& Marie Curie (Paris 6), Paris, pp. 231. https://hal.sorbonne-universite.fr/tel-01118270

Voisin M, Engel C, Viard F (2005) Differential shuffling of native genetic diversity across introduced region in a brown alga: aquaculture vs. maritime traffic effects. Proc Natl Acad Sci USA 102:54325437

Wang J (2012) Computationally efficient sibship and parentage assignment from multilocus marker data. Genetics 191:183-194

Weir BS, Cockerham CC (1984) Estimating F-statistics for the analysis of population structure. Evolution 38:1358-1370

Wiegand T, Moloney KA (2014) Handbook of spatial point-pattern analysis in ecology. CRC Press /

686 
A satellite view (Google Earth) is provided for the marina with names of the pontoons (A to I) and sea-wall sections ( 0 to 8 ) surveyed. The marina (BL: $48^{\circ} 42^{\prime} 53.932^{\prime \prime} \mathrm{N}, 3^{\circ} 57^{\prime} 52.258^{\prime \prime} \mathrm{W}$ ), farm (FB: $48^{\circ} 42^{\prime} 41.148^{\prime \prime} \mathrm{N}$, $3^{\circ} 57^{\prime} 7.919^{\prime \prime} \mathrm{W}$ ) and natural habitats (GU: 48 $42^{\prime} 43.704^{\prime \prime} \mathrm{N}, 3^{\circ} 57^{\prime} 8.748^{\prime \prime} \mathrm{W} ; \mathrm{RV}: 48^{\circ} 42^{\prime} 5.364$ 'N,

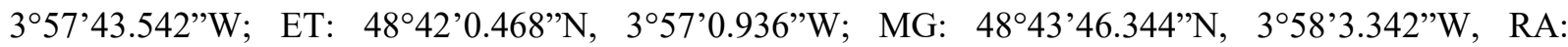
$48^{\circ} 43^{\prime} 40.908^{\prime \prime} \mathrm{N}, 3^{\circ} 58^{\prime} 19.883^{\prime \prime} \mathrm{W}$; full name and abbreviations in Suppl. Material Table S1) studied are pictured with triangle, star, and squares, respectively. Other sites were surveyed at the bay scale between 2002 and 2016: Black and white circles indicate presence (at least observed once during the survey period) and absence of $U$. pinnatifida in these sites, respectively.

\section{Fig. 2. Colonization dynamics of the marina by U. pinnatifida}

Location and number of individuals recorded on the gateway, pontoons and breakwaters over time (F14: February 2014. M14: March 2014. D14: December 2014. M15: March 2015. D15: December 2015. M16: March 2016). The grey dot in the map F14 indicates the location of 11 individuals observed on the hull of a boat in 2013 .

Fig. 3. Mark-correlation analysis of the densities recorded between two consecutive surveys (i.e., distinct generations) in the marina.

A-C-E-G: Bivariate correlation function $\mathrm{km}_{1} \mathrm{~m}_{2}$ (product of the densities), B-D-F-H: Bivariate Moran's I like correlation function (correlation coefficient). From top to bottom: (A-B) March 2014-December 2014, (C-D) December 2014-March 2015, (E-F) March 2015-December 2015, (G-H) December 2015-March 2016. Black dots: observed values. Red line: mean value expected under the local random marking null model $\left(r_{\max }=25 \mathrm{~m}\right.$ for A-D and $\mathrm{r}_{\max }=50 \mathrm{~m}$ for E-H). Grey area: global simulation envelope (199 simulations of the null model, $5^{\text {th }}$ lowest and $5^{\text {th }}$ highest values).

\section{Fig. 4. Bayesian clustering analysis (InStruct software) carried out at the bay scale.}

711 Individuals are ordered and grouped according to their habitat, sampling year and locality. Sample codes

712 start with a label for the habitat (F, M and R stands for farm, marina and rocky reef, respectively) and the 713 year of sampling. Each individual is represented by a vertical line divided into coloured segments, the 714 length of which indicates the individual's membership fraction to each of $\mathrm{K}$ clusters. Results are shown 715 for $\mathrm{K}=4$ (best likelihood). Note that for the marina in 2014, most of the individuals ( $>60)$ were found on 716 the breakwater on section S1 and S8 (B1 and B8), and thus included in the analysis, while less than 20 
717 were found on other sections and less than 10 individuals on pontoons. For the year 2015, the same

718 sections and two pontoons where most of the individuals were found have been included.

719 Fig. 5. Assignment analysis (GeneClass software) carried out at the bay scale.

720 Percentage of individuals collected in 2014 (A) and 2015 (B) assigned to sampled putative sources, in the 721 marina (black, BL), the farm (grey, FB) and natural rocky reefs (white, GU, MG, RV, RA) sampled the 722 previous years (2013 and 2014). Red bubbles (Excl.) are individuals that were excluded from all sampled 723 sources (rejected at the $1 \%$ level).

724 Fig. 6. Spatial clustering analysis of the population established in 2015 in the marina (Geneland 725 analysis).

726 A) Location of all the 291 individuals sampled in 2015. B) to F) distribution of the isoclines of the 727 membership probabilities of individuals to belong to one of the five genetic clusters identified by 728 INSTRUCT (see text). Maximum probability is in white ( $\mathrm{p}>0.9)$. 
730 N: number of individuals; Nall: mean number of alleles per loci; Ar : Allelic richness; Hobs: Observed

731 heterozygosity; He: Expected heterozygosity under Hardy-Weinberg equilibrium; $F_{\text {IS }}$ : fixation index

732 (inbreeding coefficient); $\mathrm{P}_{\mathrm{HW}}$ : probability of the exact test for Hardy-Weinberg equilibrium; $\mathrm{s}_{\mathrm{g} 2}$ :

733 population selfing rate; $\mathrm{P}_{\mathrm{s}}$ : $\mathrm{P}$-value of the test ' $\mathrm{s}_{\mathrm{g} 2}=0$ '. For natural rocky reefs, mean values over sites are

734 indicated, with details per localities provided in Table S1.

\begin{tabular}{|c|c|c|c|c|c|c|c|c|c|c|}
\hline Site & Year & $\mathbf{N}$ & Nall & Ar & Hobs & He & $\mathrm{F}_{\text {IS }}$ & $\mathbf{P}_{\text {HW }}$ & $\mathrm{S}_{\mathrm{g} 2}$ & $\mathbf{P}_{\mathrm{s}}$ \\
\hline \multirow[t]{3}{*}{ Marina } & 2013 & 11 & 2.9 & 2.7 & 0.35 & 0.33 & -0.07 & 0.86 & 0.00 & 0.67 \\
\hline & 2014 & 91 & 2.9 & 2.4 & 0.29 & 0.40 & 0.27 & $<10^{-4}$ & 0.00 & 0.52 \\
\hline & 2015 & 296 & 3.2 & 2.5 & 0.32 & 0.45 & 0.29 & $<10^{-4}$ & 0.36 & $<10^{-3}$ \\
\hline \multirow[t]{3}{*}{ Farm } & 2013 & 36 & 2.5 & 2.3 & 0.32 & 0.36 & 0.09 & 0.44 & 0.18 & 0.11 \\
\hline & 2014 & 32 & 1.5 & 1.5 & 0.26 & 0.24 & -0.07 & 0.30 & 0.14 & 0.19 \\
\hline & 2015 & 32 & 1.5 & 1.5 & 0.26 & 0.25 & -0.06 & 0.11 & 0.06 & 0.32 \\
\hline Rocky reefs & 2013 & 108 & 2.1 & 1.8 & 0.15 & 0.24 & 0.28 & n.a. & 0.39 & n.a. \\
\hline \multirow[t]{2}{*}{ (average) } & 2014 & 63 & 2.2 & 2.0 & 0.23 & 0.26 & 0.10 & n.a. & 0.56 & n.a. \\
\hline & 2015 & 145 & 2.2 & 2.0 & 0.24 & 0.30 & 0.20 & n.a. & 0.20 & n.a. \\
\hline
\end{tabular}


Figure 1.

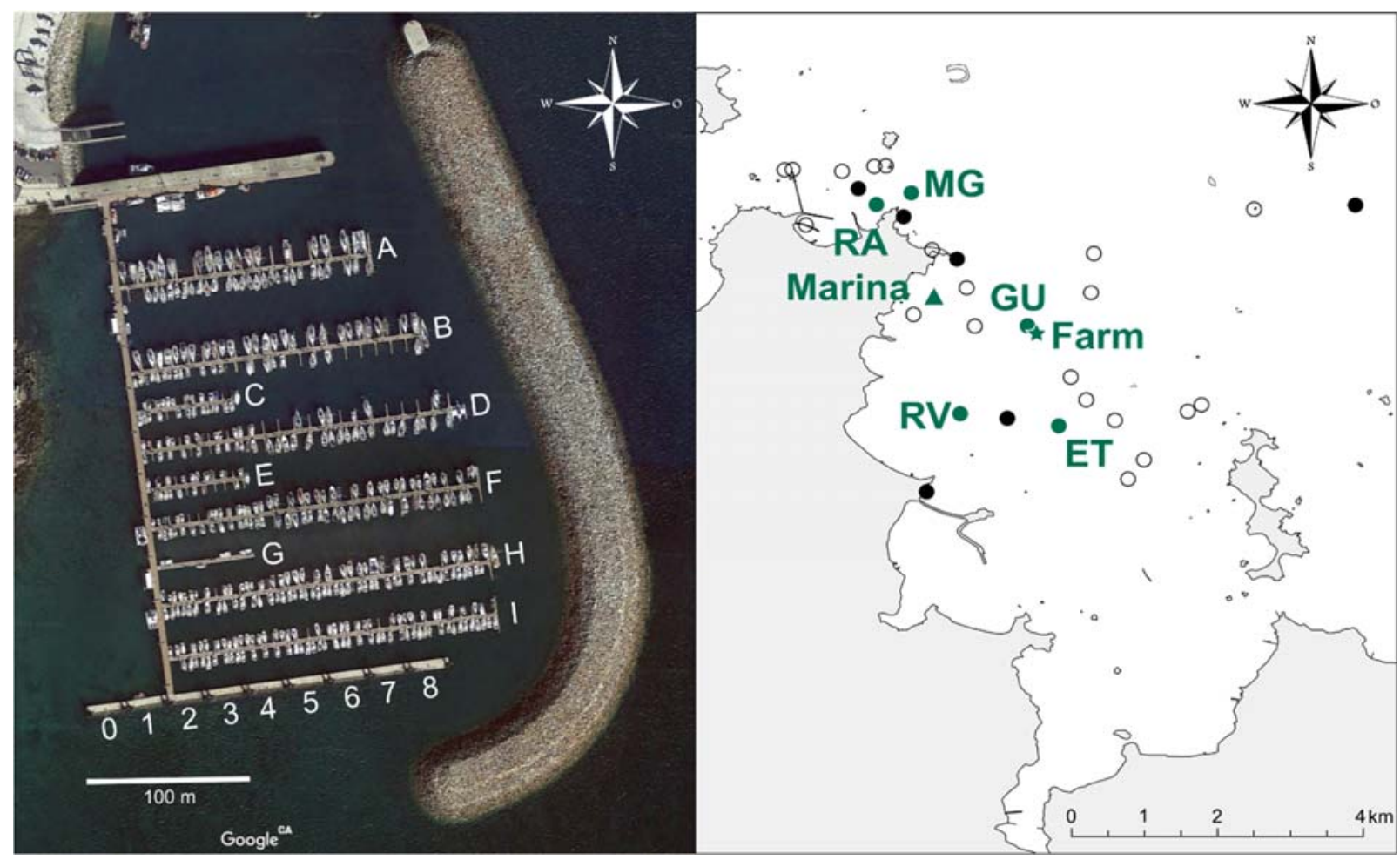


Figure 2
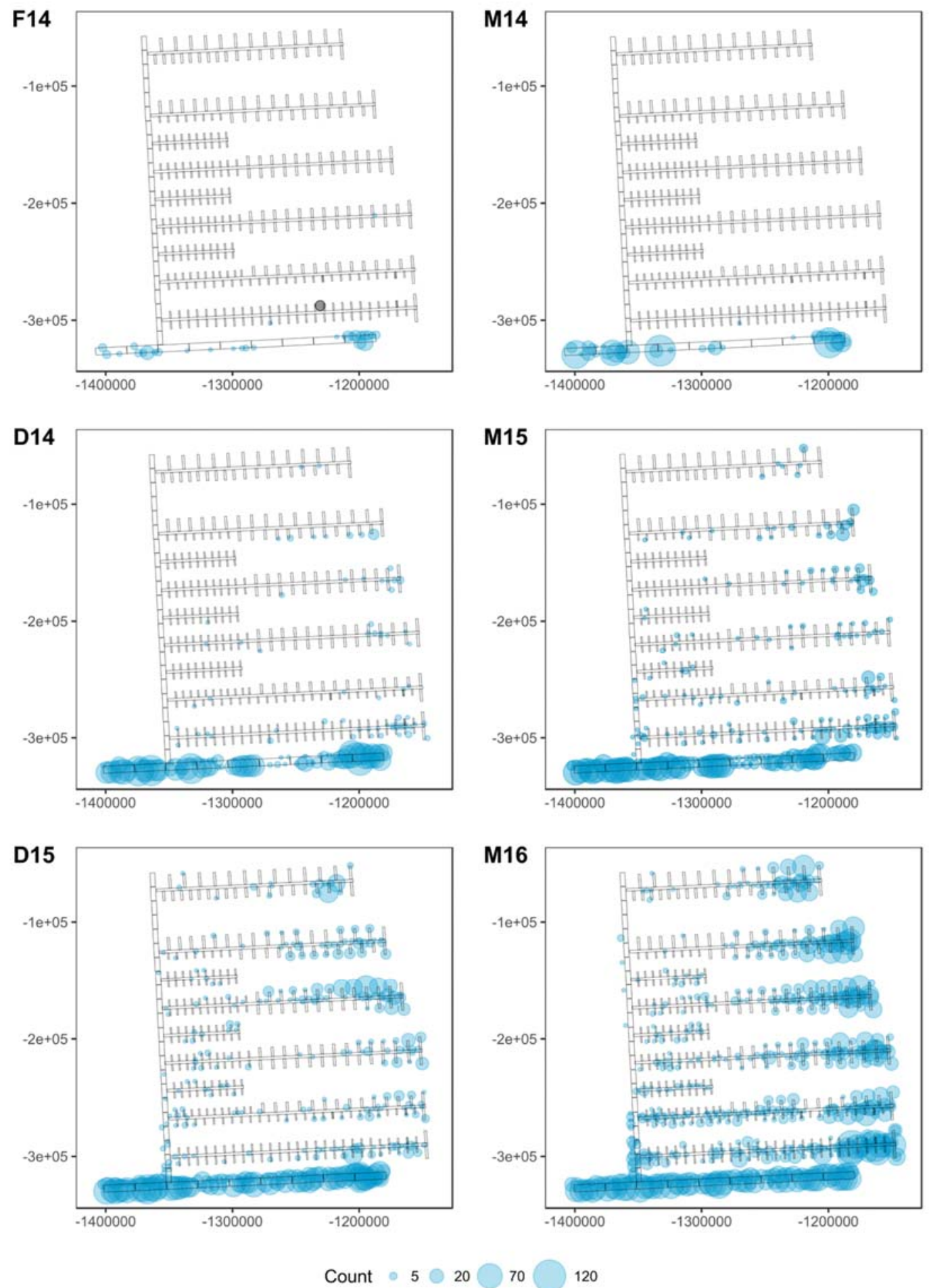
Figure 3
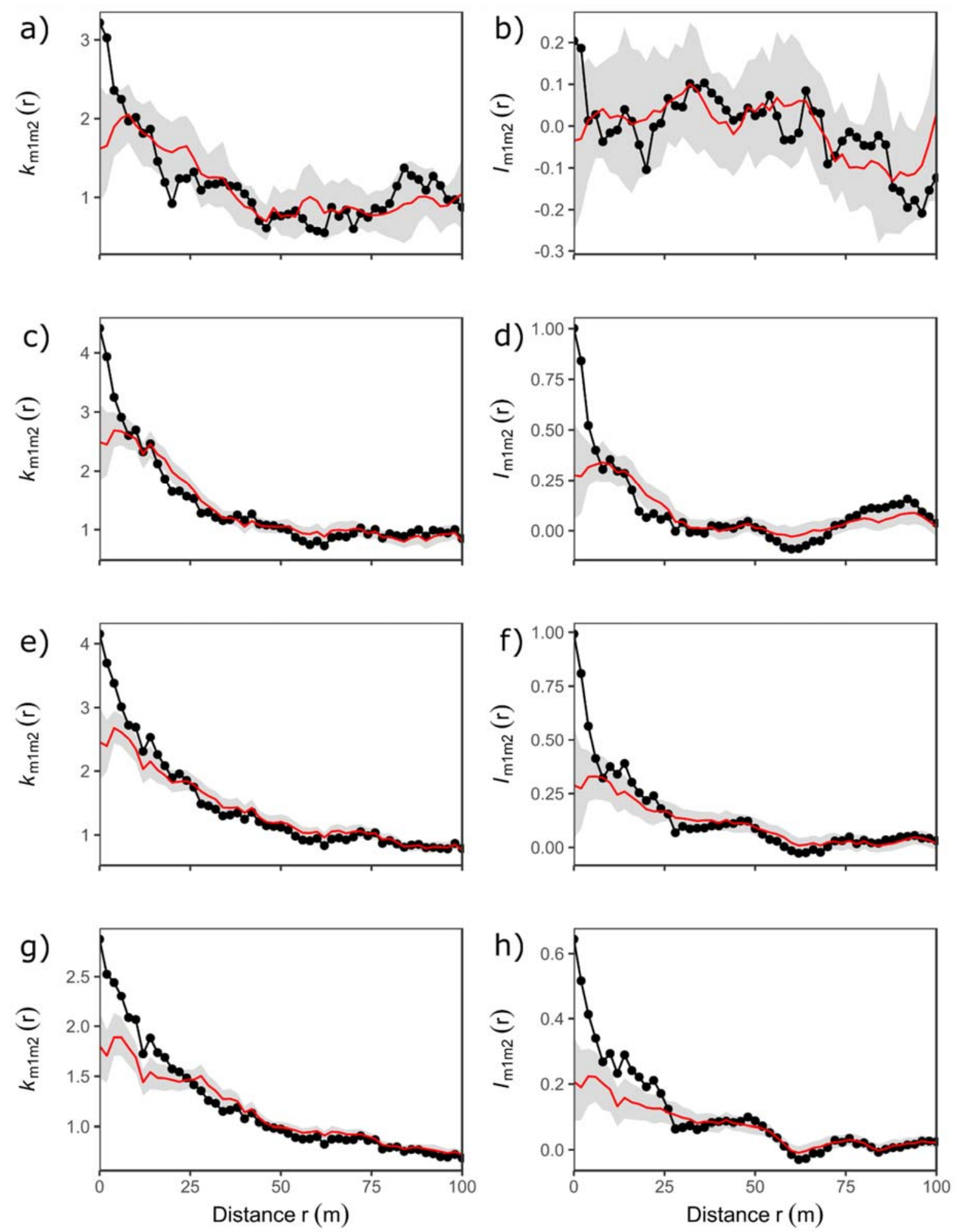


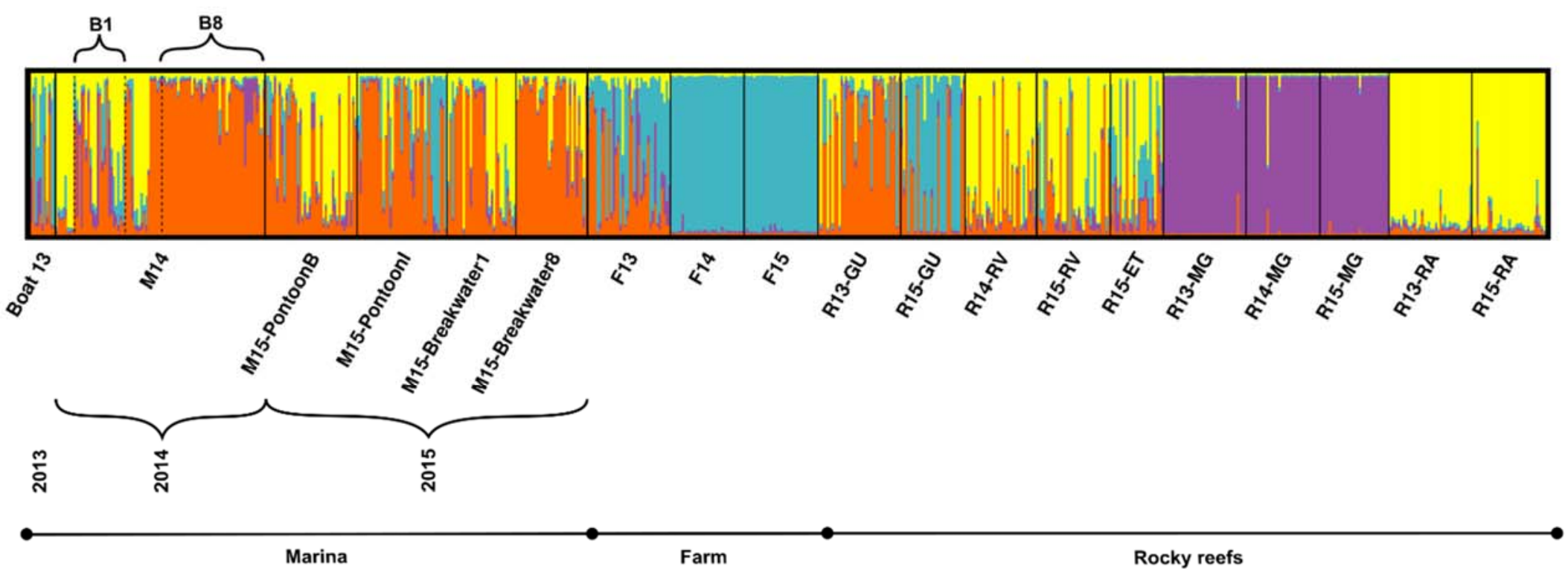

748 
Figure 5

\%Total Assigned $\cdot 0 \bigcirc 25 \bigcirc 50 \bigcirc 75$

a)

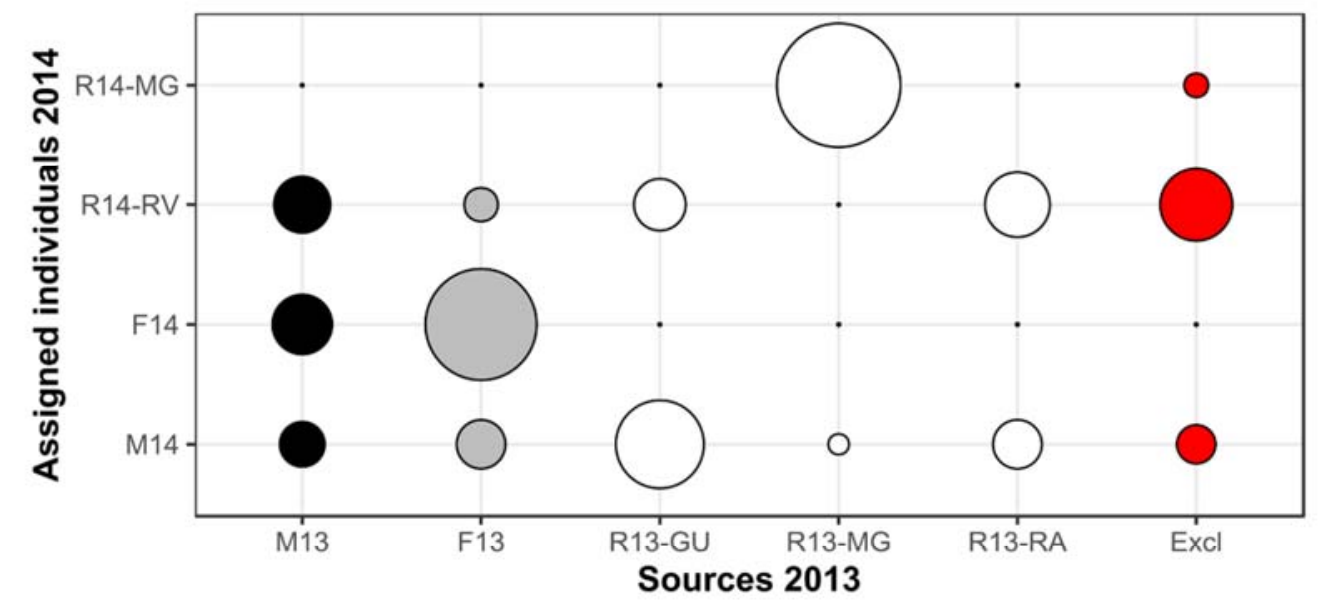

b)

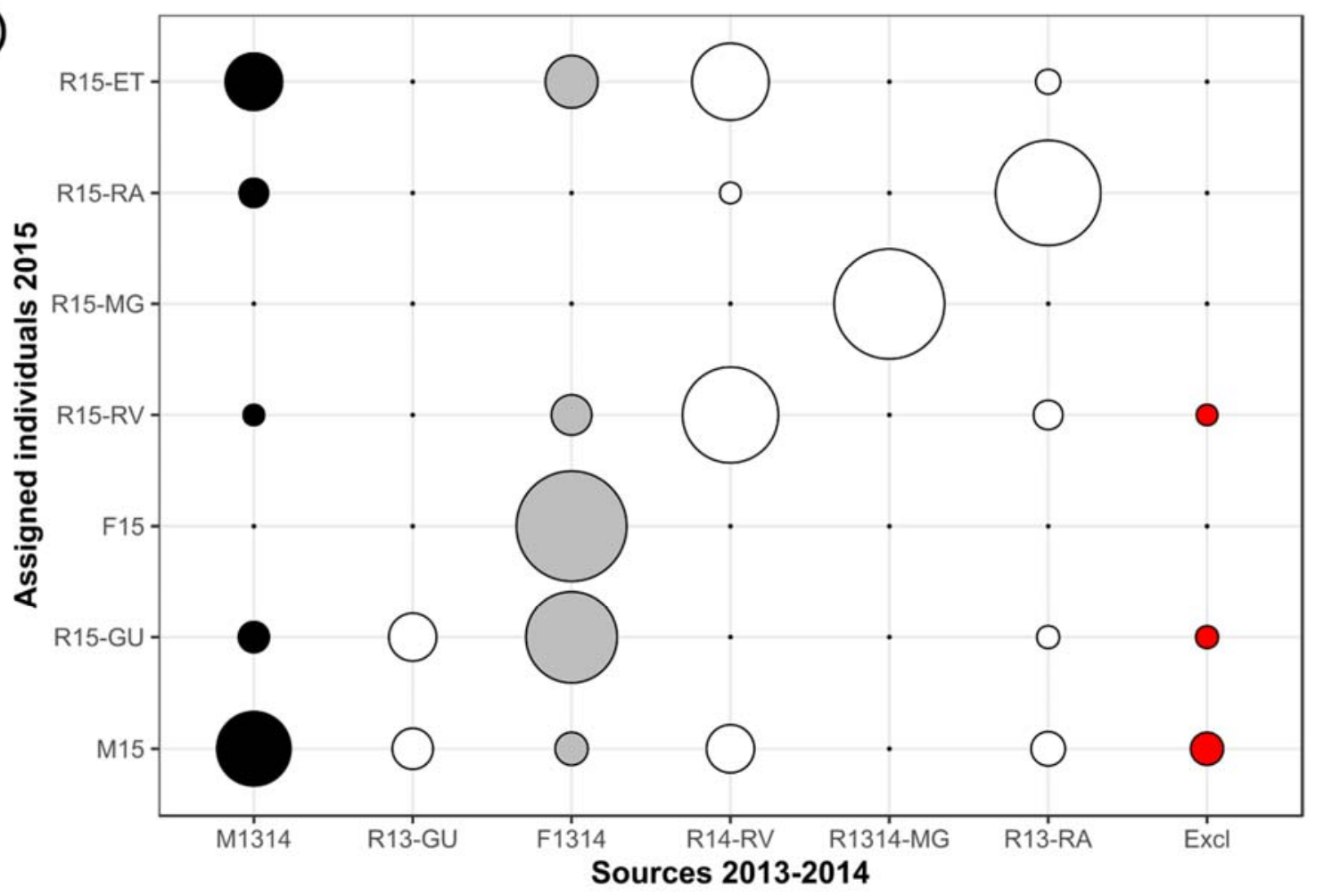


Figure 6

a)

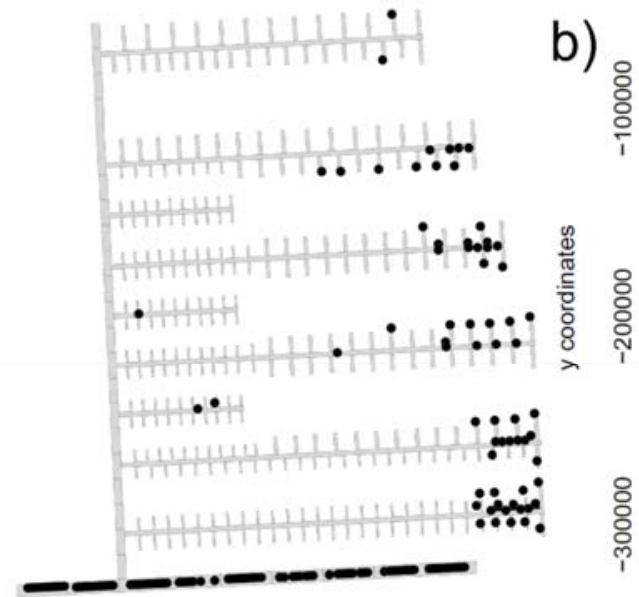

c)

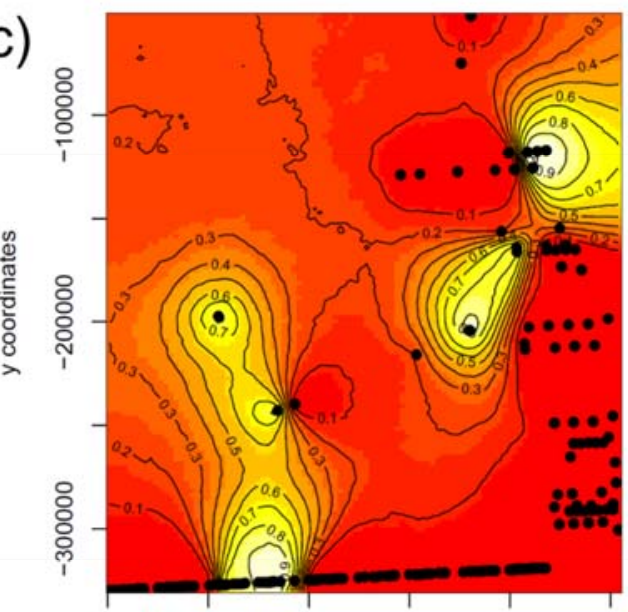

e)

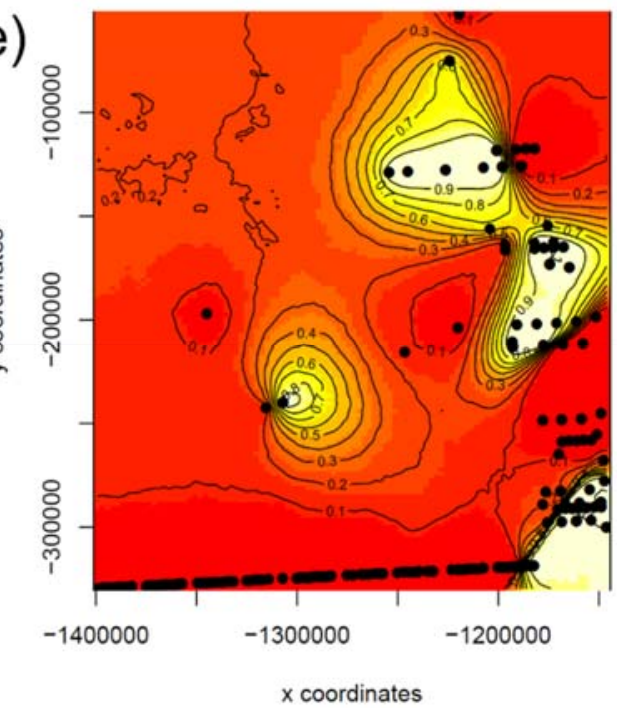

d)

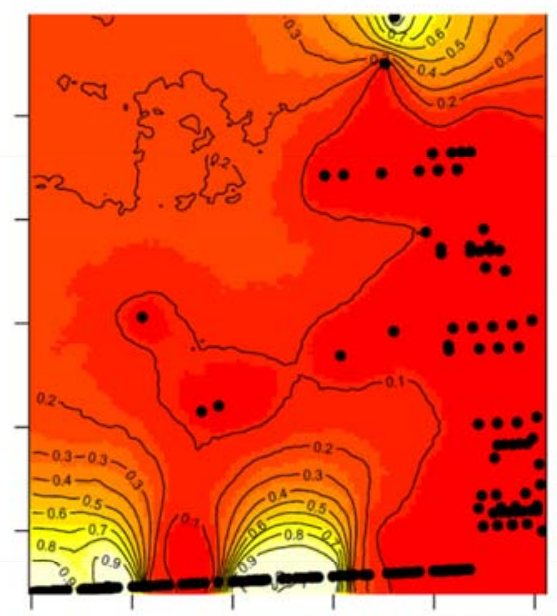

f)

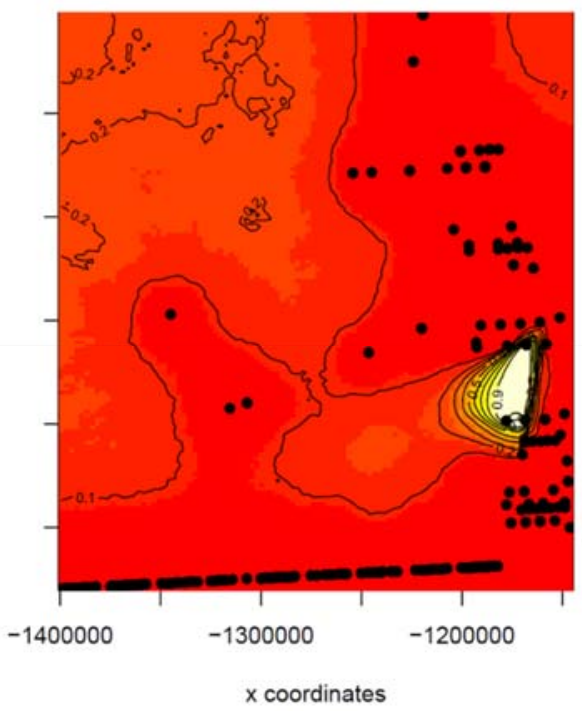


